\section{Association of polymorphisms of angiotensin I converting enzyme 2 with retinopathy in type 2 diabetes mellitus among Chinese individuals}

N Meng, Y Zhang, J MA, H Li, F Zhou and Y Qu

Department of Ophthalmology, Qilu Hospital of Shandong University, Jinan, China

Correspondence: Y Qu, Department of Ophthalmology, Qilu Hospital of Shandong University, No. 107, Wenhuaxi Road, Jinan 250012, China Tel: +8653182166150; Fax: +8653186927544. E-mail: yiqucn@sdu.edu.cn

Received: 11 May 2014 Accepted in revised form: 23 September 2014 Published online: 31 October 2014

\begin{abstract}
Aims To examine the association of Angiotensin I converting enzyme 2 (ACE2) gene polymorphisms and retinopathy in a Chinese type 2 diabetes mellitus (T2DM) cohort. Methods A total of 743 T2DM participants were involved in this study including 408 female and 335 male cases. Female cases were divided into two groups: diabetes without retinopathy (DNR group, $n=171$ ) and with retinopathy (DR group, $n=237$ ), the latter was further subclassified into nonproliferative DR (NPDR group, $n=121$ ) and proliferative DR (PDR group, $n=116$ ). Male cases were assigned to DNR group $(n=153)$ and DR group $(n=182)$ which was further grouped into NPDR group $(n=86)$ and PDR group $(n=96)$. Two single nucleotide polymorphisms (SNPs; rs2074192 and rs714205) in ACE2 gene were genotyped. Results In female cases, the frequency of genotypes TT in rs2074192 and CC in rs714205 were higher in DR and PDR group than in DNR group $(P<0.05)$. The frequency of alleles T in SNP rs2074192 and C in SNP rs714205 was higher in DR group $(P<0.05)$ and PDR group $(P<0.05)$ than in DNR group. The frequency of allele T in SNP rs2074192 was higher in PDR group $(P=0.04)$ than in NPDR group. The frequency of haplotype TC and CG was higher in DR and PDR groups, respectively $(P<0.05)$. No positive results were found in male cases. Conclusions Our results revealed that SNPs rs2074192 and rs714205 in ACE2 gene were associated with the susceptibility of DR and PDR.
\end{abstract}

Eye (2015) 29, 266-271; doi:10.1038/eye.2014.254; published online 31 October 2014

Introduction

Diabetic retinopathy (DR), one of the most common chronic ocular complications of type 2 diabetes mellitus (T2DM), often causes blindness in diabetic patients worldwide. Hyperglycemia and prolonged duration of diabetics have been deemed to be the main causes of DR. ${ }^{1}$ However, some individuals develop DR in a shorter period despite having a tight metabolic control which indicates that other factors may have a role in the development of DR. ${ }^{2}$ In the past few years, many factors, including endothelial nitric oxide synthase, receptor for advanced glycation end products, vascular endothelial growth factor and angiotensin converting enzyme were demonstrated to be involved in the development of DR. ${ }^{3-6}$

Angiotensin II (AngII), the main active peptide within the renin-angiotensin system (RAS), has been conformed to have a key role in the pathogenesis of T2DM by inhibiting the secretion of insulin, promoting the generation of inflammation and fibrosis, or producing insulin resistance. ${ }^{7-11}$ It is reported that AngII participates in the progress of retinopathy by inducing the synthesis of vascular endothelial growth factor, platelet-derived growth factor and connective tissue growth factor. ${ }^{12}$ Blockade of the RAS provides beneficial effects in terms of delaying the development and progression of diabetes and DR. 13,14

AngI converting enzyme 2 (ACE2), a novel component of RAS, as well as an ACE homolog, 
was reported to be able to degrade AngII to Ang-(I-VII) which exerts opposing actions to those of AngII. ${ }^{15,16}$ ACE2 is highly expressed in normal kidney, heart, and retina. ${ }^{15,17,18}$ Previous studies on single nucleotide polymorphisms (SNPs, rs2074192 and rs714205) in ACE2 gene and diabetic nephropathy or hypertension were conducted; ${ }^{19-21}$ however, only SNP rs2074192 was reported to be associated with diabetic hypertension in male individuals, no association was found between the two SNPs in ACE2 gene and diabetic nephropathy in either men or women. It is not clear whether ACE2 gene variants influence the retinopathy progress in T2DM cohort, and whether gender is involved. Herein, we sought to clarify the association of polymorphisms rs2074192 and rs714205 in ACE2 gene with retinopathy in a Chinese T2DM cohort.

\section{Materials and methods}

\section{Participants}

A case-control study was conducted in 743 Chinese cases with T2DM from Qilu Hospital of Shandong University including 408 female cases and 335 male cases. Since ACE2 gene is located on the $\mathrm{X}$ chromosome, female and male cases were analyzed, respectively. Female cases were divided into two groups: (1) diabetes without retinopathy (DNR) group comprised 171 patients with DNR and (2) DR group consisted 237 patients with DR, which was further subclassified into nonproliferative DR (NPDR) group with 121 patients and proliferative DR (PDR) group with 116 patients. Male cases were also assigned to DNR group containing 153 patients and DR group involving 182 DR patients, which was further grouped into NPDR group with 86 patients and PDR group with 96 patients. The diagnosis of T2DM was according to clinical features and the guidelines of the Expert Committee Report of the American Diabetes Association. ${ }^{22}$ Retinopathy status was graded according to the Early Treatment Diabetic Retinopathy Study. ${ }^{23}$ All participants were carefully assessed to ensure meeting the included criteria. The study protocol was approved by the Institutional Review Boards of Qilu Hospital of Shandong University and adhered to the tenets of the Declaration of Helsinki. All subjects gave their informed consent before anonymously participating in the study.

\section{Genotyping}

Genomic DNA was extracted from peripheral venous blood using the DNA Purification kit (TIANamp Blood DNA Kit, Tiangen Biotech, Beijing, China). ACE2 genotyping was performed using PCR-ligase detection reaction technology. The primer pairs used was as follows: rs2074192, 5'-ACTTTGCCCTTAAACACAGC-3', 5'-AAGTGTGGAAATGTATAAAT-3'; rs714205, 5' TGTGGTCTGAGAATGC-3' ${ }^{\prime}$, and $5^{\prime}$-TCCATGAG TTCTAGCCAGAC-3'. The PCR amplification was performed in the GeneAmp PCR system 9600 (Applied Biosystems, Foster City, CA, USA) in a $20-\mu 1$ reaction system and the mixture were denatured at $94{ }^{\circ} \mathrm{C}$ for $15 \mathrm{~min}$ and then 35 cycles of $94^{\circ} \mathrm{C}$ for $30 \mathrm{~s}, 56^{\circ} \mathrm{C}$ for $1 \mathrm{~min}$, and $72{ }^{\circ} \mathrm{C}$ for $1 \mathrm{~min}$ and a final extension at $72{ }^{\circ} \mathrm{C}$ for $7 \mathrm{~min}$. LDR was performed in a total volume of $10 \mu \mathrm{l}$ containing $1 \mu \mathrm{l}$ PCR product, $0.05 \mu \mathrm{l}$ Taq DNA ligase, $1 \mu \mathrm{l}$ probe mix, $1 \mu \mathrm{l}$ Taq DNA ligase buffer, and $6.95 \mu \mathrm{l}$ deionized water. The LDR conditions were $2 \mathrm{~min}$ at $95^{\circ} \mathrm{C}$ followed by 35 cycles of $30 \mathrm{~s}$ at $94^{\circ} \mathrm{C}, 2 \mathrm{~min}$ at $50^{\circ} \mathrm{C}$. The fluorescent products of ligase detection reaction were differentiated by ABI sequencer 377 (Applied Biosystems).

\section{Statistical analysis}

Clinical characteristics were compared using the student's $t$-test for continuous variables and Pearson's $\chi^{2}$-test for categorical variables. All frequency and genotype distributions of studied SNPs were tested for Hardy-Weinberg equilibrium (HWE). Distribution of allele, genotype, and haplotype frequencies of each group were estimated using $\chi^{2}$-test. Statistical analyses were conducted using SPSS version 17.0 (SPSS Inc., Chicago, IL, USA). Pair-wise linkage disequilibrium (LD) and haplotype frequency estimations were obtained using http:/ / analysis.bio-x.cn, $r^{2}$ and $D^{\prime}$ measures LD for the two investigated SNPs, and those haplotypes that exhibited a frequency $<0.03$ were ignored in analysis. Logistic regression was used to adjust the risk of DR for age, gender, blood glucose, $\mathrm{HbA} 1 \mathrm{c}$ level, and duration of disease. Odds ratios (ORs) and 95\% confidence intervals (CIs) were calculated to estimate the strength of the association. $P$-values $<0.05$ were considered nominally significant. Data were shown as mean \pm SD.

\section{Results}

Table 1 shows that significant differences existed in the duration of diabetes, systolic blood pressure, the level of blood urea nitrogen, and total cholesterol in DR group than in DNR group in the Chinese T2DM cohort $(P<0.05)$. However, no statistically significant differences were observed in age, body mass index, the level of fasting plasma glucose, hemoglobin A1c, and triacylglycero between the DR and DNR groups.

The ACE2 gene is $\mathrm{X}$ linked, herein the analyses in this study were performed on female and male subjects separately. In the female cases, the genotype distribution of the two SNPs rs2074192 and rs714205 among female cases are given in Table 2, they were in HWE in DNR and 
DR groups ( $P>0.05$, respectively). The frequency of genotype TT in SNP rs2074192 was significantly increased in DR group $(\mathrm{OR}=1.65 ; 95 \% \mathrm{CI}=1.01-2.71$,

Table 1 Clinical characteristics of type 2 diabetic patients with retinopathy (DR) and without retinopathy (DNR)

\begin{tabular}{lccc}
\hline & DR & DNR & P \\
\hline$n$ (male/female) & $419(182 / 237)$ & $324(153 / 171)$ & \\
Age (years) & $62.4 \pm 12.0$ & $60.2 \pm 11.7$ & 0.13 \\
Duration of DM (years) & $13.6 \pm 7.3$ & $10.7 \pm 7.0$ & 0.001 \\
FPG $(\mathrm{mmol} / \mathrm{l})$ & $8.9 \pm 3.8$ & $9.1 \pm 3.0$ & 0.34 \\
$\mathrm{HbA} 1 \mathrm{c}(\%)$ & $9.3 \pm 2.9$ & $8.6 \pm 2.0$ & 0.07 \\
$\mathrm{BMI}\left(\mathrm{kg} / \mathrm{m}^{2}\right)$ & $25.6 \pm 4.2$ & $26.2 \pm 4.8$ & 0.30 \\
TG $(\mathrm{mmol} / \mathrm{l})$ & $2.0 \pm 1.2$ & $2.2 \pm 1.8$ & 0.48 \\
$\mathrm{BUN}(\mathrm{mmol} / \mathrm{l})$ & $10.1 \pm 7.6$ & $5.9 \pm 3.1$ & $<0.001$ \\
TC $(\mathrm{mmol} / \mathrm{l})$ & $6.4 \pm 1.8$ & $5.1 \pm 1.6$ & $<0.001$ \\
& & & \\
BP $(\mathrm{mm} \mathrm{Hg})$ & & & $<0.001$ \\
SBP & $135 \pm 17$ & $123 \pm 21$ & $0.10<P<0.20$ \\
DBP & $78 \pm 11$ & $76 \pm 10$ &
\end{tabular}

Abbreviations: BMI, body mass index; $\mathrm{BP}$, blood pressure; $\mathrm{BUN}$, blood urea nitrogen; DBP, diastolic blood pressure; FPG, fasting plasma glucose $\mathrm{HbA1c}$, hemoglobin A1c; $n$, number of subjects; SBP, systolic blood pressure; TC, total cholesterol; TG, triacylglycerol.

Data are mean \pm SD.
$P=0.046)$ and PDR group $(\mathrm{OR}=1.97 ; 95 \% \mathrm{CI}=1.12-3.47$, $P=0.02)$ compared with DNR group, respectively. Moreover, genotype CC in rs2074192 was significantly lower in PDR group $(\mathrm{OR}=0.56 ; 95 \% \mathrm{CI}=0.32-0.98$, $P=0.04)$ than in NPDR group. No significant difference was detected on the genotype distribution of SNP rs2074192 between NPDR and DNR groups. Compared with DNR group, the frequency of genotype CC in SNP rs714205 was demonstrated significantly higher in DR group $(\mathrm{OR}=1.61 ; 95 \% \mathrm{CI}=1.004-2.59, P=0.047)$ and PDR group $(\mathrm{OR}=1.84 ; 95 \% \mathrm{CI}=1.07-3.18, P=0.03)$, respectively. However, no positive results were shown on this genotype in the comparison between groups NPDR and DNR, PDR and NPDR, respectively.

The frequencies of alleles at both loci in female T2DM cases are shown in Table 2. Compared with DNR group, the frequency of allele $\mathrm{T}$ in rs2074192 locus was significantly higher in DR group $(\mathrm{OR}=1.49 ; 95 \%$ $\mathrm{CI}=1.12-1.98, P=0.006)$ and $\mathrm{PDR}$ group $(\mathrm{OR}=1.81 ; 95 \%$ $\mathrm{CI}=1.29-2.87, P=0.0006)$, respectively. Moreover, allele $\mathrm{T}$ frequency in SNP rs2074192 was found to increase the risk of PDR compared with NPDR $(\mathrm{OR}=1.47 ; 95 \%$

Table 2 Frequencies of genotype and allele in female patients

\begin{tabular}{|c|c|c|c|c|c|c|c|c|}
\hline \multirow[t]{3}{*}{ ACE2 loci } & \multirow[t]{3}{*}{ Genotype allele } & \multirow[t]{3}{*}{$D N R(\mathrm{n}=324) ; \mathrm{n}(\%)$} & \multicolumn{6}{|c|}{ Retinopathy } \\
\hline & & & \multicolumn{2}{|c|}{ All $D R(\mathrm{n}=419)$} & \multicolumn{2}{|c|}{$N P D R(\mathrm{n}=207)$} & \multicolumn{2}{|c|}{$P D R(\mathrm{n}=212)$} \\
\hline & & & $\mathrm{n}(\%)$ & $\mathrm{P}^{\mathrm{a}}$ & $\mathrm{n}(\%)$ & $\mathrm{P}^{\mathrm{b}}$ & $\mathrm{n}(\%)$ & $\mathrm{P}$ \\
\hline \multirow[t]{7}{*}{ rs 2074192} & Genotype & & & & & & & \\
\hline & $\mathrm{CC}$ & $69(0.41)$ & $72(0.30)$ & 0.02 & $44(0.36)$ & 0.4 & $28(0.24)$ & $\begin{array}{l}0.03^{\mathrm{c}} \\
0.04^{\mathrm{d}}\end{array}$ \\
\hline & $\mathrm{CT}$ & $69(0.41)$ & $104(0.44)$ & 0.61 & $50(0.41)$ & 1 & $54(0.47)$ & $\begin{array}{l}0.38^{\mathrm{c}} \\
0.42^{\mathrm{d}}\end{array}$ \\
\hline & $\mathrm{TT}$ & $29(0.17)$ & $61(0.26)$ & 0.046 & $27(0.22)$ & 0.3 & $34(0.29)$ & $\begin{array}{l}0.02^{\mathrm{c}} \\
0.22^{\mathrm{d}}\end{array}$ \\
\hline & Allele & & & & & & & \\
\hline & $\mathrm{C}$ & $207(0.62)$ & $248(0.52)$ & 0.006 & $138(0.57)$ & 0.23 & $110(0.47)$ & $\begin{array}{l}0.0006^{\mathrm{c}} \\
0.04^{\mathrm{d}}\end{array}$ \\
\hline & $\mathrm{T}$ & $127(0.38)$ & $226(0.48)$ & & $104(0.43)$ & & $122(0.53)$ & \\
\hline \multirow[t]{7}{*}{ rs 714205} & Genotype & & & & & & & \\
\hline & $\mathrm{CC}$ & $33(0.20)$ & $67(0.28)$ & 0.047 & $31(0.26)$ & 0.23 & $36(0.31)$ & $\begin{array}{l}\mathbf{0 . 0 3 ^ { \mathrm { c } }} \\
0.36^{\mathrm{d}}\end{array}$ \\
\hline & CG & $79(0.47)$ & $114(0.48)$ & 0.83 & $57(0.47)$ & 0.99 & $57(0.49)$ & $\begin{array}{l}0.73^{\mathrm{c}} \\
0.75^{\mathrm{d}}\end{array}$ \\
\hline & GG & $56(0.33)$ & $56(0.24)$ & 0.03 & $33(0.27)$ & 0.27 & $23(0.20)$ & $\begin{array}{l}0.01^{\mathrm{c}} \\
0.18^{\mathrm{d}}\end{array}$ \\
\hline & Allele & & & & & & & \\
\hline & $\mathrm{C}$ & $145(0.43)$ & $248(0.52)$ & 0.01 & $119(0.49)$ & 0.15 & $129(0.56)$ & $\begin{array}{l}\mathbf{0 . 0 0 4 ^ { c }} \\
0.16^{\mathrm{d}}\end{array}$ \\
\hline & G & $191(0.57)$ & $226(0.48)$ & & $123(0.51)$ & & & \\
\hline
\end{tabular}

Abbreviations: DNR, diabetes without retinopathy; DR, diabetic retinopathy; NPDR, nonproliferative DR; PDR, proliferative DR.

$\chi^{2}$-Test was used to compare the genotype and allele frequencies between DR and DNR subjects.

$P$-values $<0.05$ considered to be statistically significant are shown in bold.

${ }^{\text {a All DR }}$ us DNR.

bNPDR vs DNR.

'PDR vs DNR.

dPDR vs NPDR. 
$\mathrm{CI}=1.02-1.14, P=0.04)$. In rs714205 locus, the frequency of allele $C$ was significantly higher in DR group $(P=0.01)$ and PDR group $(P=0.004)$ compared with DNR group respectively, the strength of their association with DR and PDR were indicated as $\mathrm{OR}=1.45,95 \% \mathrm{CI}=1.09-1.92$ and $\mathrm{OR}=1.65,95 \% \mathrm{CI}=1.18-2.31$, respectively.

The two investigated SNPs were in LD with each other (DR vs DNR: $r^{2}=0.83, D^{\prime}=1.00$; PDR vs DNR: $r^{2}=0.80$, $D^{\prime}=1.00$; NPDR $v s$ DNR: $\left.r^{2}=0.85, D^{\prime}=1.00\right)$. Haplotype frequencies of the two loci among female T2DM subjects are summarized in Table 3. Of the haplotypes constructed, three were found to be common, and were included in subsequent analysis. Significantly increased frequency of haplotype TC was seen in DR $(\mathrm{OR}=1.49$; 95\% $\mathrm{CI}=1.12-1.98, P=0.006)$ and PDR groups (OR $=1.81 ; 95 \% \mathrm{CI}=1.29-2.54, P=0.0006)$ compared with DNR, respectively. Meanwhile, reduced frequency of haplotype CG were found in DR $(\mathrm{OR}=0.68$; $95 \%$ $\mathrm{CI}=0.52-0.90, P=0.008)$ and $\mathrm{PDR}$ groups $(\mathrm{OR}=0.60$;
95\% CI $=0.43-0.84, P=0.003)$. No significant differences were found in NPDR compared with DNR.

No significance was observed on the frequency distribution analyses of genotypes and alleles at both loci among male T2DM subjects (Table 4).

\section{Discussion}

Some studies have been conducted to report the association between polymorphisms (SNPs, rs2074192 and rs714205) in ACE2 gene and diabetic nephropathy or hypertension. ${ }^{19-21}$ It is not clear whether ACE2 gene variants influence the retinopathy progress in T2DM cohort. In this study, we analyzed these two SNPs in the ACE2 gene in T2DM patients.

This study showed a strong correlation of SNPs rs2074192 and rs714205 polymorphism in ACE2 gene with DR and PDR in Chinese female T2DM patients, not in male T2DM patients. The ACE2 gene is located on

Table 3 Analysis of haplotype frequency for rs2074192 and rs714205 in female patients

\begin{tabular}{|c|c|c|c|c|c|c|c|}
\hline \multirow[t]{3}{*}{ Haplotypes rs2074192/rs714205 } & \multirow[t]{3}{*}{$D N R \mathrm{n}(\%)$} & \multicolumn{6}{|c|}{ Retinopathy } \\
\hline & & \multicolumn{2}{|c|}{ All $D R$} & \multicolumn{2}{|c|}{$P D R$} & \multicolumn{2}{|c|}{$N P D R$} \\
\hline & & $\mathrm{n}(\%)$ & $\mathrm{P}^{\mathrm{a}}$ & $\mathrm{n}(\%)$ & $\mathrm{P}^{\mathrm{b}}$ & $\mathrm{n}(\%)$ & $\mathrm{P}^{\mathrm{c}}$ \\
\hline $\mathrm{C} / \mathrm{C}$ & $22(4.6)$ & $16(4.8)$ & 0.92 & $7(3.0)$ & 0.29 & $15(6.2)$ & 0.46 \\
\hline $\mathrm{C} / \mathrm{G}$ & $226(47.7)$ & $191(57.2)$ & 0.008 & 103 (44.4) & 0.003 & $123(50.8)$ & 0.13 \\
\hline $\mathrm{T} / \mathrm{C}$ & $226(47.7)$ & $127(38.0)$ & 0.006 & $122(52.6)$ & 0.0006 & $104(43.0)$ & 0.23 \\
\hline
\end{tabular}

Abbreviations: DNR, diabetes without retinopathy; DR, diabetic retinopathy; NPDR, nonproliferative DR; PDR, proliferative DR.

Frequency $>0.03$ in both DR and DNR groups has been involved to calculate the odds ratio and $95 \%$ confidence interval.

$P$-values $<0.05$ considered to be statistically significant are shown in bold.

${ }^{\mathrm{a}} P$ : DNR $v S \mathrm{DR}$.

${ }^{\mathrm{b}} P$ : DNR $v S$ PDR.

${ }^{c} P$ : DNR vs NPDR.

Table 4 Frequencies of allele in male patients

\begin{tabular}{|c|c|c|c|c|c|c|c|c|}
\hline \multirow[t]{3}{*}{ ACE2 loci } & \multirow[t]{3}{*}{ Genotypes allele } & \multirow[t]{3}{*}{$D N R(\mathrm{n}=324) \mathrm{n}(\%)$} & \multicolumn{6}{|c|}{ Retinopathy } \\
\hline & & & \multicolumn{2}{|c|}{ All $D R(\mathrm{n}=419)$} & \multicolumn{2}{|c|}{$N P D R(\mathrm{n}=207)$} & \multicolumn{2}{|c|}{$P D R(\mathrm{n}=212)$} \\
\hline & & & $\mathrm{n}(\%)$ & $\mathrm{P}^{\mathrm{a}}$ & $\mathrm{n}(\%)$ & $\mathrm{P}^{\mathrm{b}}$ & $\mathrm{n}(\%)$ & $\mathrm{P}$ \\
\hline \multirow[t]{3}{*}{ rs 2074192} & Male & & & & & & & \\
\hline & C & $92(0.61)$ & $111(0.61)$ & 0.95 & $56(0.65)$ & 0.56 & $55(0.57)$ & $\begin{array}{l}0.53^{\mathrm{c}} \\
0.28^{\mathrm{d}}\end{array}$ \\
\hline & $\mathrm{T}$ & $58(0.39)$ & $71(0.39)$ & & $30(0.35)$ & & $41(0.43)$ & \\
\hline \multirow[t]{3}{*}{ rs 714205} & Male & & & & & & & \\
\hline & C & $58(0.39)$ & $73(0.40)$ & 0.79 & $30(0.35)$ & 0.56 & $43(0.45)$ & $\begin{array}{l}0.34^{\mathrm{c}} \\
0.17^{\mathrm{d}}\end{array}$ \\
\hline & G & $92(0.61)$ & $109(0.60)$ & & $56(0.65)$ & & $53(0.55)$ & \\
\hline
\end{tabular}

Abbreviations: DNR, diabetes without retinopathy; DR, diabetic retinopathy; NPDR, nonproliferative DR; PDR, proliferative DR.

$\chi^{2}$-Test was used to compare the genotype and allele frequencies between DR and DNR subjects.

a All DR vs DNR.

${ }^{\mathrm{b}}$ NPDR vs DNR.

c PDR vs NPDR.

${ }^{\mathrm{d}} \mathrm{PDR}$ vs NPDR. 
chromosome $\mathrm{Xp} 22$ and consists of 18 exons and 17 introns, which infers its gender characteristics. ${ }^{24}$ Therefore, we analyzed the two SNPs in female and male, respectively. In the female group, the genotypes TT or CC and alleles T or C in SNPs rs2074192 or rs714205 were demonstrated as risk genotypes or alleles in DR and PDR; however, minor homozygous genotype CC in SNP rs2074192 was shown protective on PDR individuals.

Moreover, strong LD was detected between the two loci. The haplotype TC comprised by the risk alleles of the two SNPs was significantly higher in DR group, especially in PDR group, whereas the protective haplotype CG was significantly over represented in DNR group. It is a crucial finding that SNPs rs2074192 and rs714205 in the ACE2 gene were associated with the susceptibility to DR and PDR in the Chinese female T2DM cohort. The minor homozygous genotype in SNP rs2074192 can reduce the risk of PDR. We also found that TC or CG may be the risk or protective haplotypes of DR subjects, especially PDR subjects.

To the best of our knowledge, this is the first study to investigate the association of ACE2 gene polymorphism with DR in T2DM. It is demonstrated that ACE2 cleaves AngII to form Ang-(I-VII) with a high catalytic efficiency; whereafter, Ang-(I-VII) exerts opposing actions to those of AngII by inhibiting vasoconstriction and cell proliferation and consequently protect the retina. ${ }^{16,25}$ The reduction of serum level of Ang-(I-VII) may reduce the protective function on retina and cause the occurrence and development of DR. In this study, we found that ACE2 gene variants were probably involved in the pathogenesis of DR and PDR in the Chinese female T2DM cohort. The possible reason may be that the variants rs2074192 and rs714205 located on the intron area of ACE2 gene which may affect the expression of $A C E 2$ gene by regulating the splicing of mRNA and eventually results in the decrease of serum level of Ang-(I-VII).

As we know, gender and sex hormones can probably affect the components of the RAS, ${ }^{26}$ ACE2 is one of the components of RAS gene that is located on $X$ chromosome. ${ }^{27}$ The escapes of $X$ inactivation are reported on many genes may contribute to the sexual differences of ACE2 gene in this Chinese T2DM cohort. ${ }^{27}$

In conclusion, the present study demonstrates that the ACE2 gene polymorphisms rs2074192 and rs714205 are correlated with DR in the Chinese female T2DM cohort. The two SNPs can increase the susceptibility of DR and PDR. The minor homozygous genotype at SNP rs2074192 can reduce the risk of PDR. Moreover, the risk and protective haplotypes comprised by the two SNPs were found in DR. Further researches focusing on the exact biological mechanism and other possible factors underlying the association of the ACE2 gene with DR in T2DM individuals are needed to be confirmed in the future.

\section{Summary}

What was known before

- Previous studies on single nucleotide polymorphisms (SNPs, rs2074192 and rs714205) in ACE2 gene and diabetic nephropathy or hypertension were conducted.

What this study adds

- This is the first study to report the association of ACE2 gene polymorphisms with diabetic retinopathy in Chinese type 2 diabetes mellitus individuals.

\section{Conflict of interest}

The authors declare no conflict of interest.

\section{Acknowledgements}

This study was supported partly by Natural Science foundation of Shandong Province (ZR2013HZ003) and Scientific and Technologic Project of Jinan, Shandong (201302025). The authors thank the subjects who participated in the study.

\section{References}

1 Brownlee M. Biochemistry and molecular cell biology of diabetic complications. Nature 2001; 414: 813-820.

2 Uthra SRR, Mukesh BN. Genetics of diabetic retinopathy. Int J Hum Genet 2008; 8: 155-159.

3 Warpeha KM, Xu W, Liu L, Charles IG, Patterson CC, Ah-Fat $\mathrm{F}$ et al. Genotyping and functional analysis of a polymorphic (CCTTT)(n) repeat of NOS2A in diabetic retinopathy. Faseb J 1999; 13: 1825-1832.

4 Hudson BI, Stickland MH, Grant PJ. Identification of polymorphisms in the receptor for advanced glycation end products (RAGE) gene: prevalence in type 2 diabetes and ethnic groups. Diabetes 1998; 47: 1155-1157.

5 Duh E, Aiello LP. Vascular endothelial growth factor and diabetes: the agonist versus antagonist paradox. Diabetes 1999; 48: 1899-1906.

6 Migdalis IN, Iliopoulou V, Kalogeropoulou K, Koutoulidis K, Samartzis M. Elevated serum levels of angiotensinconverting enzyme in patients with diabetic retinopathy. South Med J 1990; 83: 425-427.

7 Carlsson PO, Berne C, Jansson L. Angiotensin II and the endocrine pancreas: effects on islet blood flow and insulin secretion in rats. Diabetologia 1998; 41: 127-133.

8 Singh VP, Le B, Khode R, Baker KM, Kumar R. Intracellular angiotensin II production in diabetic rats is correlated with cardiomyocyte apoptosis, oxidative stress, and cardiac fibrosis. Diabetes 2008; 57: 3297-3306.

9 Ogihara T, Asano T, Ando K, Chiba Y, Sakoda H, Anai M et al. Angiotensin II-induced insulin resistance is associated with enhanced insulin signaling. Hypertension 2002; 40: 872-879.

10 Marrero MB, Fulton D, Stepp D, Stern DM. Angiotensin II-induced insulin resistance and protein tyrosine phosphatases. Arterioscler Thromb Vasc Biol 2004; 24: 2009-2013. 
11 Olivares-Reyes JA, Arellano-Plancarte A, Castillo-Hernandez JR. Angiotensin II and the development of insulin resistance: implications for diabetes. Mol Cell Endocrinol 2009; 302: 128-139.

12 Wilkinson-Berka JL. Angiotensin and diabetic retinopathy. Int J Biochem Cell Biol 2006; 38: 752-765.

13 Cooper ME, Tikellis C, Thomas MC. Preventing diabetes in patients with hypertension: one more reason to block the renin-angiotensin system. J Hypertens Suppl 2006; 24: S57-S63.

14 Sjolie AK, Klein R, Porta M, Orchard T, Fuller J, Parving HH et al. Effect of candesartan on progression and regression of retinopathy in type 2 diabetes (DIRECT-Protect 2): a randomised placebo-controlled trial. Lancet 2008; 372: 1385-1393.

15 Donoghue M, Hsieh F, Baronas E, Godbout K, Gosselin M, Stagliano $\mathrm{N}$ et al. A novel angiotensin-converting enzymerelated carboxypeptidase (ACE2) converts angiotensin I to angiotensin 1-9. Circ Res 2000; 87: E1-E9.

16 Raizada MK, Ferreira AJ. ACE2: a new target for cardiovascular disease therapeutics. J Cardiovasc Pharmacol 2007; 50: 112-119.

17 Burrell LM, Johnston CI, Tikellis C, Cooper ME. ACE2, a new regulator of the renin-angiotensin system. Trends Endocrinol Metab 2004; 15: 166-169.

18 Verma A, Shan Z, Lei B, Yuan L, Liu X, Nakagawa T et al. ACE2 and Ang-(1-7) confer protection against development of diabetic retinopathy. Mol Ther 2012; 20: 28-36.

19 Patel SK, Wai B, Ord M, MacIsaac RJ, Grant S, Velkoska E et al. Association of ACE2 genetic variants with blood pressure, left ventricular mass, and cardiac function in Caucasians with type 2 diabetes. Am J Hypertens 2012; 25: 216-222.
20 Currie D, McKnight AJ, Patterson CC, Sadlier DM, Maxwell AP. Investigation of ACE, ACE2 and AGTR1 genes for association with nephropathy in Type 1 diabetes mellitus. Diabet Med 2010; 27: 1188-1194.

21 Frojdo S, Sjolind L, Parkkonen M, Makinen VP, Kilpikari R, Pettersson-Fernholm $\mathrm{K}$ et al. Polymorphisms in the gene encoding angiotensin I converting enzyme 2 and diabetic nephropathy. Diabetologia 2005; 48: 2278-2281.

22 Expert Committee on the Diagnosis and Classification of Diabetes Mellitus. Report of the expert committee on the diagnosis and classification of diabetes mellitus. Diabetes Care 2003; 26(Suppl 1): S5-20.

23 Grading diabetic retinopathy from stereoscopic color fundus photographs-an extension of the modified Airlie House classification. ETDRS report number 10. Early Treatment Diabetic Retinopathy Study Research Group. Ophthalmology 1991; 98: 786-806.

24 Hamming I, Cooper ME, Haagmans BL, Hooper NM, Korstanje R, Osterhaus AD et al. The emerging role of ACE2 in physiology and disease. J Pathol 2007; 212: $1-11$.

25 Wysocki J, Ye M, Rodriguez E, Gonzalez-Pacheco FR, Barrios $\mathrm{C}$, Evora $\mathrm{K}$ et al. Targeting the degradation of angiotensin II with recombinant angiotensin-converting enzyme 2: prevention of angiotensin II-dependent hypertension. Hypertension 2010; 55: 90-98.

26 Fischer M, Baessler A, Schunkert H. Renin angiotensin system and gender differences in the cardiovascular system. Cardiovasc Res 2002; 53: 672-677.

27 Carrel L, Willard HF. X-inactivation profile reveals extensive variability in $\mathrm{X}$-linked gene expression in females. Nature 2005; 434: 400-404. 